\title{
Determination of Absorbed Dose Results from Radioactive Waste Sampling and Assay
}

\author{
Saad Mohammed Abd, Taha Yaseen Mansoor, Hussein Saady Al-Daffaie \\ Radioactive Waste Treatment and Management Directorate, Ministry of Science and Technology, Baghdad, Iraq \\ Email address: \\ saad_m196711@yahoo.com (S. M. Abd) \\ To cite this article: \\ Saad Mohammed Abd, Taha Yaseen Mansoor, Hussein Saady Al-Daffaie. Determination of Absorbed Dose Results from Radioactive Waste \\ Sampling and Assay. American Journal of Mechanics and Applications. Vol. 6, No. 1, 2018, pp. 23-26. doi: 10.11648/j.ajma.20180601.15
}

Received: December 29, 2017; Accepted: March 5, 2018; Published: March 23, 2018

\begin{abstract}
There has been great concern about the health risks associated with exposure to radioactivity present in soil, thus in this present study, absorbed dose rate measurements were carried out at some selected samples of contaminated soil. The purpose is to examine to what extent such measurements can be used to delineate the effect radiation to the workers and to assess the radiation risk of radioactive waste management personnel by calculating the annual dose of external radiation exposure and the amount of radioactive dose absorbed by the workers. Ladlum detector used to measure the exposure dose rate $(\mu \mathrm{R} / \mathrm{h})$. The germanium system was used to analyze the samples collected from the decontamination processes, the activity concentration ranged from (1026.21 to 25961.5$) \mathrm{Bq} / \mathrm{kg}$. The value of the annual dos rate vary between (5.55E-05 to.40E-03) $\mathrm{Sv} / \mathrm{h}$.
\end{abstract}

Keywords: External Dose Rate, Absorbed dose Rate, Activity Concentration

\section{Introduction}

Radioactive waste (RW) is generated from various processes related to nuclear programs. In addition to industrial, agricultural and scientific research, oil and gas extraction fields as well as by increasing the natural radioactivity of natural radionuclides in the soil at the permissible limits [1]. These isotopes can seep into soil as a result of natural or unnatural factors (negligence), or because of lack of knowledge of radiation protection and the risk of such, such cases have been generated. This leads to radiation exposure. Therefore, the two main pathways that lead to radiation exposure to the general public because of the "consequences" are the external exposure of radionuclides deposited on the ground and internal exposure by eating contaminated food produced in polluted areas. It is very important to assess environmental pollution as well as the risks of external and internal exposure caused by nuclear disasters for radiation prevention and public health. On the other hand, the risk of external exposure around the living space has become a matter of public interest to confirm the safety of life. Therefore, in order to assess the current environmental pollution and contributions from external exposure due to radioactive industrial radionuclides, and the transfer of these radionuclides to the soil leads to the cause of pollution, and therefore should be treated as areas contaminated and must conduct decontamination operations, can be used and the activities of decontamination processes to achieve several objectives, such as the reduction of occupational radiation exposure, and reduce the potential release of pollutants on the environment, and allow the re-use of components, and facilitate waste management. In order to properly manage the $\mathrm{RO}$, it must implement the acceptance requirements, standards or waste specifications for further waste treatment and the general protection standard for occupational radiation. [2]. The main purpose of the safety assessment is to determine whether an adequate level of safety of an facility or activity has been achieved and whether the basic safety objectives and safety standards developed by the designer, operator and regulatory body have been met [3].

The objective of this paper is to calculate the rate of absorbed dose in selected soil models and their impact on workers. The unit $\mathrm{C}$ used to measure the absorbed dose is gray (Gy). 


\section{Method}

For the evaluation of external radiation exposure, undisturbed surface soils were collected by a core sampling technique (12 samples at soil depths of $0-5$ and $5-10 \mathrm{~cm}$ ). The quantity of soil collected in each sample was $500 \mathrm{~g}$. After collection, all samples were dried by a fixed temperature dryer $(120 \mathrm{C}, 24 \mathrm{~h})$ and sieved for pebbles and organic materials $(2 \mathrm{~mm})$ before measurement of radionuclide activity. After preparation, samples were put in plastic containers made of polypropylene and analyzed with a highpurity germanium detector (ORTEC, Ortec International Inc., Detector efficiency calibration for different measurement geometries was performed using mixed activity standard volume sources (mix standard sample). The relative detection efficiency of this instrument was $40 \%$. The calibration was carried out by counting standard radionuclides of known activities with well-defined energies within the energy range of interest from $60 \mathrm{keV}$ to $2000 \mathrm{keV}$ and used standard source for efficiency calibration of gamma ray spectrometer in measuring large volumes of low specific activity materials [4]. Sample collection, processing and analysis were executed in accordance with standard methods of IAEA.

\section{Results}

The following steps have been adopted:

\subsection{Measurements of Specific Activity}

The activity concentration of radionuclide at the soil was measured using spectrometer with a coaxial high purity germanium detector (GC2018-7500 SL). It has a relative efficiency of $40 \%$, and a resolution of $1.8 \mathrm{keV}$ for $1332 \mathrm{keV}$ gamma ray emission of ${ }^{60} \mathrm{Co}$. Gene software for gamma spectrum analysis a gamma spectrometer and relevant accessories were supplied by [5].

\subsection{Doses from External Exposure}

The external exposures, kinds of radiation of concern are those sufficiently penetrating to traverse the overlying tissues of the body and deposit ionizing energy in radiosensitive organs and tissues. Penetrating radiations are limited to photons, including bremsstrahlung, and electrons. The radiation dose depends strongly on the temporal and spatial distribution of the radionuclide to which a human is exposed.

The external dose from exposure to radionuclides in the soil can be calculated with the following equation [6]:

$$
D_{E X T}=C_{\text {soil }} * \rho_{\text {soil }} * D C C_{E X T} * H
$$

where,

$\mathrm{D}_{\text {jext }}$ is the dose from the $j$-th radionuclide via external exposure $\left[\mathrm{S}_{\mathrm{v}} / \mathrm{y}\right]$,

$\mathrm{C}_{\mathrm{j} \text { soil }}$ is the concentration of the $j$-th radionuclide in soil $[\mathrm{Bq} / \mathrm{kg}]$,

$\rho_{\text {soil }}$ is the soil density $\left[\mathrm{kg} / \mathrm{m}^{3}\right]$,

$\mathrm{H}$ is the exposure time to external radiation $[\mathrm{h} / \mathrm{y}]$,

$\mathrm{DCC}_{\text {jext }}$ is the dose coefficient for external exposure of the $j$-th radionuclide $\left[\mathrm{S}_{\mathrm{v}} / \mathrm{h}\right.$ per $\left.\mathrm{Bq} / \mathrm{m}^{3}\right]$ [7].

The value density of the soil is $1600 \mathrm{~kg} / \mathrm{m} 3$, dos conversion Coefficients ( DCC) is $1.3 \mathrm{E}-13 \mathrm{~Sv} / \mathrm{h}$ per $\mathrm{Bq} / \mathrm{m} 3$ ) for external exposure

While the exposure time for the worker in the field (radiation characterization) per year is 260 hours.

\subsection{Absorbed Dose Rate}

Absorbed radiation dose at selected of the contaminated soil samples, were measured using a survey meter. Ludlum Model 19 Micro R Meter, USA was used to measure the gamma dose rates at 1 meter above the ground of sampling location. The instrument has linear energy responses to gamma radiation between 0.08 and $1.2 \mathrm{MeV}$ [8]. It covered the majority of gamma ray emissions from major sources. The instrument uses scintillator, $2.5 \times 2.5 \mathrm{~cm}$ ( 1 x 1 in.) (Dia $x$ L) thick Nal. The survey meters were calibrated at the Malaysian Nuclear Agency, which is recognised by the IAEA as a Secondary Standards Dosimetry Laboratory. The meter display was in microroentgen per hour ( $\mu \mathrm{R}$ h-1). The gamma dose rate in unit $\mu \mathrm{R} \mathrm{h}^{-1}$ was converted to unit $\mu \mathrm{Gy} \mathrm{h} \mathrm{h}^{-1}(1 \mu \mathrm{R}$ $\mathrm{h}^{-1}=0.00964 \mu \mathrm{Gy} \mathrm{h}^{-1}$ ).

A radionuclide, ingested or inhaled, and distributed in various parts of the body.

One can measure absorbed dose rate in medium by using formula (1).

$$
\text { Absorbed dose }(n G y / h) \text { in medium }=\text { Dose rate }(\mu R / h) * 9.64 E-3
$$

Many radionuclides follow specific metabolic pathways, acting as a chemical element, and localize in specific tissues. If an internally deposited radionuclide emits particles that have a short range, then their energies will be absorbed in the tissue that contains them. The rate of energy absorption per gram tissue is $\mathrm{A} E\left(\mathrm{MeV} \mathrm{g}^{-1} \mathrm{~s}^{-1}\right)$.

The absorbed dose rate calculated by using equation [9]:

$$
D^{\cdot}=1.60 \times 10^{-10} \times A \times E G y s^{-1}
$$

Where:

$\mathrm{D}$ is the absorbed dose rate in Gy. $\mathrm{s}^{-1}, A$ is the average concentration, in $\mathrm{Bq} \mathrm{g}^{-1}$, of the radionuclide in the tissue and
$E$ is the average beta-particle energy, in $(0.696 \mathrm{MeV}$ per disintegration.

\section{Discussions}

Exposure to ionizing radiation may cause biological hazards to workers in the processes and practices of radioactive waste management, including the removal of areas contaminated by industrial isotopes due to poor control of radiation or unintentional neglect.

The method has been used to calculate absorbed dose rate and annual dose rate of gamma dose rate in this study area. 
the reading was taken from far at $50 \mathrm{~cm}$ from the radioactive waste sample by using Ludlum detector. The exposure dose rate of gamma ranges was from 103 to $5560 \mu \mathrm{R}$. h-1 as show in table 1 . The annual external radiative exposure values for the workers were from (5.55 E-05 to.40E-03) Sv / h. In view of the calculated values, we conclude that the readings are within the permissible limit of exposure of workers, which is $20 \mathrm{mSv} / \mathrm{y}$ approved in the publications of the International Atomic Energy Agency ( IAEA ) and the International Commission on Radiological Protection ( ICRP ). From figure 1 one can show the value of annual external dose rate in sample (6) is the higher value and value of sample (5) is the lower value. The values of the absorbed dose were among the values that are not of concern and are among the permissible values. The value of absorbed dose one can show in table 2.

From Figure 2 we observe a direct increase between the values of radiation exposure and the absorbed dose from exposure to the workers.

Finally, all values for the external exposure or the dose allowed for workers resulting from dealing with the radioactive waste under study are within acceptable limits.

Table 1. Data base of external exposure dose.

\begin{tabular}{llll}
\hline Item & Dose Rate $(\boldsymbol{\mu R \mathbf { h }})$ & Activity concentration $\mathbf{( B q} / \mathbf{k g})$ & External dose $(\mathbf{S v} / \mathbf{y})$ \\
\hline 1 & 103 & 6649.57 & $3.60 \mathrm{E}-04$ \\
2 & 920 & 7551.3 & $4.08 \mathrm{E}-04$ \\
3 & 228 & 3074.75 & $1.66 \mathrm{E}-04$ \\
4 & 325 & 6014.65 & $3.25 \mathrm{E}-04$ \\
5 & 135 & 1026.21 & $5.55 \mathrm{E}-05$ \\
6 & 5560 & 25961.5 & $1.40 \mathrm{E}-03$ \\
7 & 650 & 7012.73 & $3.79 \mathrm{E}-04$ \\
8 & 730 & 7724.24 & $4.18 \mathrm{E}-04$ \\
9 & 458 & 5305.125 & $2.87 \mathrm{E}-04$ \\
10 & 320 & 4077.77 & $2.21 \mathrm{E}-04$ \\
11 & 830 & 8613.62 & $4.66 \mathrm{E}-04$ \\
12 & 924 & 9449.64 & $5.11 \mathrm{E}-04$ \\
\hline
\end{tabular}

Table 2. The value of absorbed dose rate.

\begin{tabular}{lll}
\hline Sample Item & Exposure Dose Rate $(\boldsymbol{\mu R I h})$ & Absorbed dose rate $(\mathbf{n G y} / \mathbf{h})$ \\
\hline 1 & 103 & 988.8 \\
2 & 920 & 8832 \\
3 & 228 & 2188.8 \\
4 & 325 & 3120 \\
5 & 135 & 1296 \\
6 & 5560 & 53376 \\
7 & 650 & 6240 \\
8 & 730 & 7008 \\
9 & 458 & 4396.8 \\
10 & 320 & 3072 \\
11 & 830 & 7968 \\
12 & 924 & 8870.4 \\
\hline
\end{tabular}

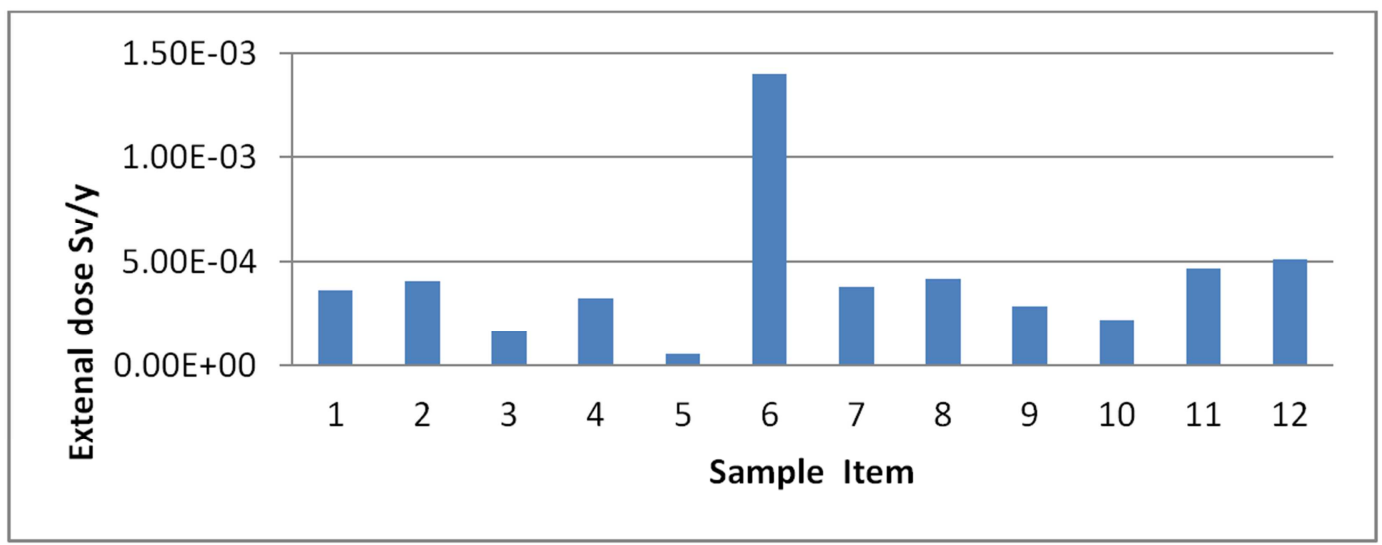

Figure 1. The external dose rate value of the sample. 


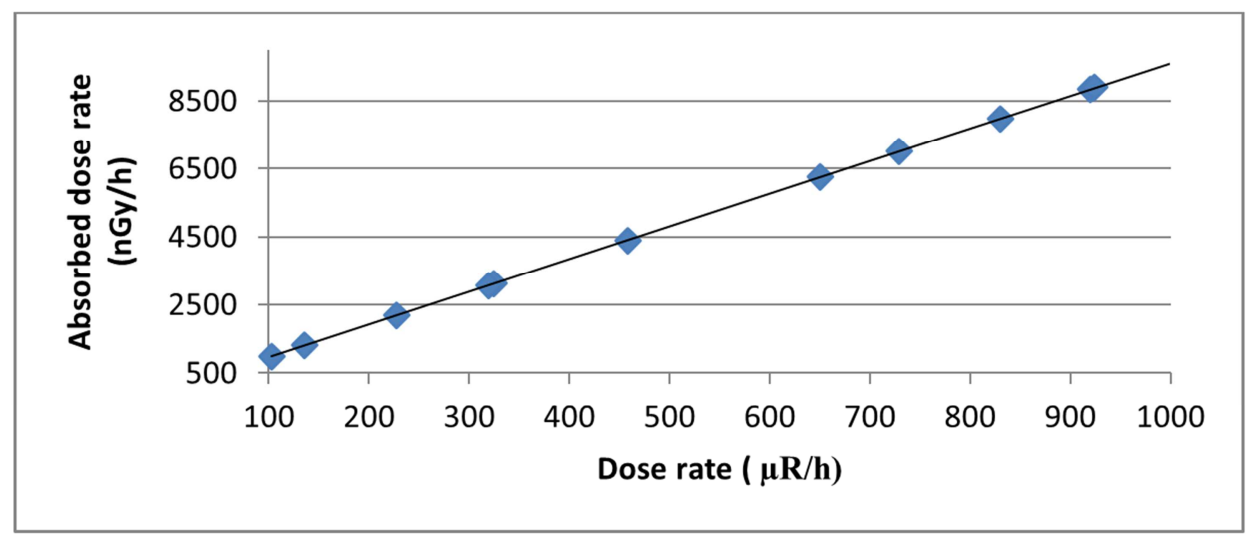

Figure 2. The relation between Absorbed dose rate and exposure dose rate of the sample.

\section{Conclusion}

One of the main things in dealing with radioactive materials and their waste is to know the method of measurements of conducting field radiation, in addition to the measurements of the samples of contaminated models and the method of analysis in the right way. From this we will ensure the safety of workers in the field of radiation or in the laboratory of the risk of unjustified radiation exposure.

In this work we note from the attached results, whether related to radiological doses from different types or radiological analysis of the models taken from the work area, not found any radiation exposure to the workers requires other operations to ensure the safety of workers, in comparison with [10] and [11].

\section{References}

[1] International Commission on Radiological Protection, Annals of the ICRP (Feb 23, 2012), Occupational Intakes of Radionuclides, Part 1.

[2] International Atomic Energy Agency, Iaea-Tecdoc-1817, Selection of Technical Solutions for The Management of Radioactive Waste, TECDOC-1817, Vienna, 2017.

[3] Emad S. Shamsaldin, Asia H. Al-Mashhadani and Saad M. Abd (2014), Risk assessment for retrieving legacy radioactive waste in Al-Tuwaitha site, Advances in Applied Science Research, 5 (5):29-38.

[4] International Atomic Energy Agency (IAEA), "Measurement of Radionuclides in Food and the Environment". Technical Report Series No. 295, Vienna: IAEA Publication, VIENNA, 1989.

[5] Canberra, USA, Enhanced Capability ultra-light. Portable HaHeld Radioisotope Identifier.

[6] Odolfo Avila, Facilia AB, Methodology for calculation ofdoses to man and mplementation in Pandora, Ulla Bergström, Swepro Project Management AB, ISSN 14023091 SKB Rapport R-06-68, July 2006.

[7] Eckerman and Legget 1996.

[8] Glenn F. Knoll, Radiation Detection and Measurement, Fourth Edition, Wiley, 2010.

[9] James E. Turner, Atoms, Radiation, and Radiation Protection, Third, Completely Revised and Enlarged Edition, ISBN 9783-527-40606-7, USA.2007.

[10] International Commission on Radiological Protection. The 2007 Recommendations of the International Commission on Radiological Protection. Annals of the ICRP 37 (2-4). ICRP Publication 103. Pergamon Press, Oxford, 2007.

[11] National Council on Radiation Protection and Measurements (NCRP), Ionizing Radiation Exposure of the Population of the United States, NCRP Report No. 160 U.S. NCRP, Washington D. C. 2009. 